\title{
Interaction Between Florfenicol and Doxycycline Involving Cytochrome P450 3A in Goats (Capra hricus)
}

\author{
Xiaojing Wang ${ }^{1}$, Yaqin Yang ${ }^{2}$, María-Aránzazu Martínez ${ }^{3}$, Marta Martínez ${ }^{3}$, \\ Bernardo Lopez-Torres ${ }^{3}$, Maria-Rosa Martínez-Larrañaga ${ }^{3}$, Xu Wang ${ }^{1,2 *}$, Arturo Anadón ${ }^{3 *}$ \\ and Irma Ares $^{3}$ \\ ${ }^{1}$ National Reference Laboratory of Veterinary Drug Residues (HZAU) and MAO Key Laboratory for Detection of Veterinary \\ Drug Residues, Huazhong Agricultural University, Wuhan, China, ${ }^{2}$ MOA Laboratory for Risk Assessment of Quality and \\ Safety of Livestock and Poultry Products, Wuhan, China, ${ }^{3}$ Department of Pharmacology and Toxicology, Faculty of Veterinary \\ Medicine, Universidad Complutense de Madrid, Madrid, Spain
}

\section{OPEN ACCESS}

Edited by:

Valentina Meucci,

University of Pisa, Italy

Reviewed by:

Benito Soto-Blanco,

Federal University of Minas

Gerais, Brazil

Wilson Kiiza Rumbeiha,

University of California, Davis,

United States

*Correspondence:

Xu Wang

wangxu@mail.hzau.edu.cn

Arturo Anadón

anadon@vet.ucm.es orcid.org/0000-0002-0580-7204

Specialty section:

This article was submitted to Veterinary Pharmacology and Toxicology,

a section of the journal

Frontiers in Veterinary Science

Received: 16 August 2021 Accepted: 21 September 2021 Published: 18 October 2021

Citation:

Wang $X$, Yang $Y$, Martínez $M-A$,

Martínez M, Lopez-Torres $B$, Martínez-Larrañaga $M-R$, Wang $X$, Anadón A and Ares I (2021) Interaction Between Florfenicol and Doxycycline Involving Cytochrome P450 3A in Goats (Capra hricus).

Front. Vet. Sci. 8:759716. doi: 10.3389/fvets.2021.759716
When two drugs are combined, drug-drug interactions (DDI) often occur. Metabolic DDI usually occur due to inhibition of the metabolism of one drug by the other. This leads to an increase in the plasma concentration of the drug whose metabolism is inhibited. The objective of this research study was to verify the DDI risk of two antibacterial, florfenicol (FF) and doxycycline (DOX) due to metabolism. Because food containing residues of any pharmacologically active substance could potentially constitute a public health hazard, we selected a food producing animal, goat, goat liver microsomes and recombinant metabolic enzymes, for in vivo and in vitro metabolism studies. In vitro experiments showed that CYP3A was the key enzyme subfamily in FF metabolism, DOX slowed down FF metabolism and R440 was possibly the key amino acid in the metabolic interaction between FF and DOX. In vivo studies in the goats showed that DOX inhibited up-regulation of CYP3A24 gene expression produced by FF; in liver and kidney, DOX slightly slowed down FF metabolism. Quantitative prediction of DDI risk suggest that when DOX is used in combination with FF in veterinary medicine, may result in a clinical significant increase of FF plasma and tissue concentrations, resulting a prevalence of harmful tissue residues of medicinal products in the food chain. Through our experimentation, when DOX is used in combination with FF, the withdrawal period of FF in the kidney was extended by 1 day. Otherwise, an appropriate withdrawal period (20 days) of FF was established for FF and DOX combined use to ensure that the animal can be safely slaughtered for food.

Keywords: florfenicol, florfenicol amine, doxycycline, metabolism, interaction, CYP3A, residue depletion study

\section{INTRODUCTION}

Florfenicol (FF), 2-dichloro-N-\{(1R,2S)-3-fluoro-1-hydroxy-1-4-(methylsulfonyl) phenyl] propan2 -yl\} acetamide, is a synthetic, broad-spectrum, primarily bacteriostatic antibiotic, of choice for the treatment of pneumonia and associated respiratory infections in livestock $(1,2)$. It is indicated in goats for the treatment of respiratory infections caused by Mannheimia haemolytica, Pasteurella multocida, and Histophilus somni associated with pyrexia $(3,4)$. The total FF residue in the tissue is calculated as the sum of FF and florfenicol amine (FFA). According to the European Union Regulation (EU) (5), the maximum residue limits (MRLs) of FF in goats are as follows: muscle 
$(200 \mu \mathrm{g} / \mathrm{kg})$, liver $(3,000 \mu \mathrm{g} / \mathrm{kg})$ and kidney $(300 \mu \mathrm{g} / \mathrm{kg})$. The MRL represents one of several standard options for risk managers to limit the presence of unwanted substances.

One of appropriate and suitable methods that would increase the effectiveness of chemotherapy of bacterial infections is a rational use of a combination of antimicrobial agents. Combination of antimicrobial agents is often presented as one of the few remaining effective strategies for the treatment of clinical diseases for which standard treatments have become ineffective. When two or more drugs are combined, the combinational effect can be defined as synergism, no interaction, or antagonism. Doxycycline (DOX), $\alpha$-6-deoxy-5hydroxytetracycline, a "second-generation" tetracycline, is also a primarily bacteriostatic antibiotic indicated in gastrointestinal and respiratory tract infections $(6,7)$. The combined use of FF and DOX has a synergistic or additive effect, both are usually combined to improve their efficacy. A study was conducted to study in vitro (P. multocida isolates) synergism of FF with DOX. The results reveal that synergistic interactions were observed in $15 \%$ of the tested isolates for FF + DOX. Consideration of synergism plus fractional inhibitory concentration index produced higher overall percentages of FF + DOX (69\%) combination (8).

However, when more than one drug is used concurrently in combination therapy, drug-drug interactions (DDI) may occur, especially if their metabolism involves overlapping mechanisms (9). Cytochrome P450 (CYP450) enzyme-based drug metabolism is a key factor in DDI (10). Existing studies have shown that FF metabolism in rabbits and chickens is affected by CYP3A, and when P450 enzyme substrates, inhibitors or inducers are added, the drugs may interact and cause adverse effects (11, 12). In addition, studies have shown that DOX can inhibit the metabolism of quinine to 3-OH quinine via CYP3A (13). That is, DOX is likely to have an inhibitory effect on CYP3A. However, the possibility of DDI between DOX and FF under the influence of CYP3A has not yet been investigated.

Studies on the pharmacokinetics of FF in goats are relatively extensive, but there are few studies on the detection of FF tissue residues and the recommended withdrawal period $(14,15)$. The "withdrawal period" means the minimum period between the last administration of a veterinary medicinal product to an animal and the production of foodstuffs from that animal which under normal conditions of use is necessary to ensure that such foodstuffs do not contain residues in quantities harmful to public health (16).

With the gradual expansion of meat goat herds, goat meat has become an increasingly important animal-derived food, and its tissue residues have also received widespread attention (17). In this study, in vitro and in vivo experiments were carried out in goats to evaluate the DDI produced when DOX and FF are combined.

\section{MATERIALS AND METHODS}

\section{Bacteria and Plasmid}

Escherichia coli BL21 (DE3) and E. coli DH5 $\alpha$ were purchased from Vazyme (Nanjing, China). Plasmid pET-28a was obtained from the National Reference Laboratory of Veterinary Drug Residues (HZAU), Wuhan, China.

\section{Experimental Methods Goat Liver Microsomes Experiments}

Goat liver microsomes were purchased from PrimeTox Bio-medical Technology Co. LTD (Wuhan, China). The protein concentration was $20 \mathrm{mg} / \mathrm{kg}$ and the activity of the microsomes was appropriate. To determine the key metabolic enzymes of FF metabolism, we used six CYP450 inhibitors: ketoconazole (CYP3A4), diosmetin (CYP1A), quinidine (CYP2D6), fomepizole (CYP2E1), methoxsalen (CYP2A6), and sulfaphenazole (CYP2C9) were co-incubated with $\mathrm{FF}$ in goat liver microsomes. In order to study the effect of DOX on FF, we divided the experiment into a single group of florfenicol and a combined group of florfenicol and doxycycline. Both of these two combinations were incubated with goat liver microsomes. The production of FFA was determined by liquid chromatography tandem mass spectrometry (LC-MS/MS). Each reaction was performed in triplicate.

\section{Cloning of the CYP3A24 Gene}

According to the mRNA sequence of goat CYP3A24, specific primers (forward: 5' -cagcaaatgggtcgcggatccATGGAGCTAATC CCAAGCTTTTC-3' and reverse: $5^{\prime}$-gtggtggtggtggtgctcgagGGC TCCACTTATGGTTCCATCTC-3') were designed containing restriction enzyme sites $B a m H$ I and Xho I to amplify the coding sequence of CYP3A24. The goat CYP3A24 gene fragment was obtained by polymerase chain reaction (PCR) and ligated into the expression plasmid pET-28a. The ligated plasmid pET28a-CYP3A24 was used to transformed E. coli DH5 $\alpha$. Isolated transformant was cultured and the recombinant plasmid was confirmed by sequencing.

\section{Homology Modeling and Molecular Docking}

Using the homology modeling phantom of the Sybyl-X2.0 software (Tripos, USA), the 3D structure of goat CYP3A24 was obtained based on the crystal structure of the human CYP3A4 protein (PDB ID: 4D7D). Sybyl-X2.0 was also used for molecular docking of the CYP3A24 protein with FF and DOX to obtain the key amino acids (AA) involved in the formation of hydrogen bonds between the protein and each drug (AA within $5 \AA$ of the active pocket are considered possible AA related to affinity) (18).

\section{Site-Directed Mutagenesis}

The steps for site-directed mutagenesis were as follows: First, the recombinant plasmid pET-28a-CYP3A24 was used as a template to obtain the required mutant plasmid PCR, and the primers used to introduce the mutation are shown in Table 1. Second, the mutant plasmid was digested with the restriction enzyme Dpn I and then used to transform E. coli DH5 $\alpha$ cells (19). Third, the mutant plasmid was transformed into E. coli BL21 (DE3) for recombinant expression and then sequenced for confirmation.

The protein expression and purification process of bacteria was based on the published article of our laboratory (18). Then, the purified proteins were concentrated through concentrator tubes and confirmed by SDS-PAGE and Western blot. The 
protein concentration of each sample was determined by the method of Bradford (20).

\section{The Protein Activity Verification of CYP3A24 and Its Mutants}

Testosterone (TS) is a specific substrate of CYP3A, which can generate $6 \beta$-OHTS under the action of CYP3A (21). In order to study the protein activity of CYP3A24 and its mutants, we incubated each protein with TS. The experimental steps were as follows: protein $(0.5 \mathrm{mg} / \mathrm{mL})$ and NADPH $(1 \mathrm{mmol} / \mathrm{L})$ were added to PBS ( $\mathrm{pH} \mathrm{7.4)}$ ) for $10 \mathrm{~min}$ at $37^{\circ} \mathrm{C}$, then TS (Dr. Ehrenstorfer $\mathrm{GmbH}$, Germany, $1 \mu \mathrm{mol} / \mathrm{L}$ ) was added to start the reaction. The total reaction volume was $200 \mu \mathrm{L}$. At $60 \mathrm{~min}$ after drug addition, $200 \mu \mathrm{L}$ of ice-cold acetonitrile was added to terminate the reaction. After centrifugation at $12,000 \mathrm{~g} / \mathrm{min}$ for $15 \mathrm{~min}$, the supernatant was filtered through a $0.22 \mu \mathrm{m}$ membrane and analyzed by LC-MS/MS (AB SCIEX API5000, USA). For TS and 6 $\beta$-OHTS, chromatographic separation occurred using a Thermo Scientific Hypersil Gold C18 column $(150 \times 2.1 \mathrm{~mm}, 5 \mu \mathrm{m}$ particles $)$, and analytes were detected on an API5000 mass analyser. Mobile phase A was $0.1 \%$ formic acid in water, and mobile phase $\mathrm{B}$ was methanol. The mass spectrometric parameters for TS and $6 \beta$-OHTS was shown in Table 2 . The flow rate was $0.2 \mathrm{~mL} / \mathrm{min}$ with a linear gradient under the following conditions: $0-0.10 \mathrm{~min} 5-85 \% \mathrm{~B}, 0.10-4.10 \mathrm{~min} 85 \%$ $\mathrm{B}, 4.10-8.00 \mathrm{~min} 85-5 \% \mathrm{~B}$. The injection volume was set to $10 \mu \mathrm{L}$. The limit of quantitation (LOQ) of the analysis was $0.1 \mu \mathrm{mol} / \mathrm{L}$, and the limit of detection (LOD) of the analysis was $0.02 \mu \mathrm{mol} / \mathrm{L}$. All inter-assay coefficients of variation were within $8.6 \%$, the intra-assay coefficients of variation were within $12.4 \%$, and the recovery rates were between 84.5 and $115.4 \%$.

TABLE 1 | Primers used for site-directed mutagenesis.

\begin{tabular}{ll}
\hline Primer & Sequence (from $\mathbf{5}^{\prime}$ to $\mathbf{3}^{\prime}$ end) \\
\hline R105A & F: TTCACAAACGCGAGGGTITTGGTCCAATGGG \\
& R: AAAAACCCTCGCGTTGTGAAGACAGAGT \\
R372A & F: ATTGCTGTTCACTTGATAGGCTCTGTAAGAAGGATG \\
& R: CCTATCAAGTCAACAGCAATTGAAACATTCTGAGAGTC \\
R440A & F: ACTGGACCCGCAATTGCATTGGCATGAGGTTG \\
& R: AATGCAATITGGGGTCAGTCCAAAAGCAGGT \\
\hline
\end{tabular}

The underline shows the bases corresponding to the mutant amino acids, all primers were synthesized by Sangon Biotech (Shanghai, China).

TABLE 2 | Optimized characteristic ion mass spectrometry parameters for TS and $6 \beta$-OHTS.

\begin{tabular}{lcccc}
\hline Drug & Polarity & $\begin{array}{c}\text { Precursor } \\
\text { ion } \mathbf{( m / z )}\end{array}$ & $\begin{array}{c}\text { Product } \\
\text { ion } \mathbf{( m / z )}\end{array}$ & $\begin{array}{c}\text { Collision } \\
\text { energy }(\mathbf{V})\end{array}$ \\
\hline TS & Positive & 289.0 & 109.0 & 20 \\
& & & 97.0 & 35 \\
$6-\beta \mathrm{OH}-\mathrm{TS}$ & Positive & 305.1 & 269.3 & 20 \\
& & & 184.0 & 25
\end{tabular}

After activity verification, CYP3A24 and its mutants were coincubated with FF and DOX, and the key amino acid residues for metabolism of FF and DOX were studied by the determination of FFA production.

\section{Animal Experimental Design}

In this study, a total of 54 Boaer-cross goats (Capra hircus) of both sexes, about 8 months old, were selected, weighing $28-36 \mathrm{~kg}$. During the 1st week of acclimatization, all animals were raised in the usual way, with free access to feed and water. The experiment was conducted in accordance with the Guidelines for the Care and Use of Laboratory Animals issued by HZAU and approved by the Ethics Committee of Veterinary College of HZAU.

Throughout the experiment, all goats had ad libitum access to feed and water without antibiotics. The goats were divided into three groups, namely the control group (6 animals), the single group (24 animals), and the combined group (24 animals). The control group was fed without medication. In the single group, FF (Zhonglongshenli Animal Pharmaceutical Co., Ltd. Hefei, China, specification: $10 \mathrm{~mL}: 1 \mathrm{~g}$ ) was injected into the neck muscles at $48 \mathrm{~h}$ intervals, twice in total. In the combined group, FF was injected into the neck muscles at $48 \mathrm{~h}$ intervals, twice in total, and DOX-hyclate (Zhonglongshenli Animal Pharmaceutical Co., Ltd. Hefei, China, specification: $10 \mathrm{~mL}$ : $1 \mathrm{~g}$ ) was injected into the neck muscles, once a day for 3 days. The volume of the treatment solution was calculated individually for each goat to provide a dose equivalent to $20 \mathrm{mg} \mathrm{FF} / \mathrm{kg}$ bw and $10 \mathrm{mg}$ $\mathrm{DOX} / \mathrm{kg}$ bw.

The control group was euthanized by use of ketamine hydrochloride (Fujian Gutian Pharmaceutical Co. Ltd., China: $10-15 \mathrm{mg} / \mathrm{kg} \mathrm{bw}$ ) and xilazine hydrochloride (Shengda Animal Medicine Co. Ltd., China: $2 \mathrm{mg} / \mathrm{kg}$ bw) for anesthesia followed by euthanasia with T61 (Bayer Animal Health GmbH, Germany: 4-6 mg/50 kg bw) and tissue samples (liver, kidney and muscle) were collected and were used to the validation of the analytical method for the compounds FF and FFA.

TABLE 3 | Primers sequences of goat CYP3A24 and $\beta$-actin for qPCR.

\begin{tabular}{ll}
\hline Gene & Primer sequences $\left(\mathbf{5}^{\prime}\right.$ to $\mathbf{3}^{\prime} \mathbf{)}$ \\
\hline CYP3A24 & F: ATGCAATTCGGGGTCCAGT \\
& R: GGCACCTCCGACCTATGATG \\
$\beta$-actin & F: GGACTTCGAGCAGGAGATGG \\
& R: CCAGGAAGGAAGGCTGGAAG
\end{tabular}

All primers were synthesized by Sangon Biotech (Shanghai, China).

TABLE 4 | Optimized characteristic ion mass spectrometry parameters for FF and FFA.

\begin{tabular}{lllcc}
\hline Drug & Polarity & Precursor ion & Product ion & Collision energy \\
\hline FF & Positive & \multirow{2}{*}{355.9} & 336.1 & 22 \\
& & & 118.8 & 35 \\
FFA & Positive & \multirow{2}{*}{247.9} & 229.7 & 18 \\
& & & 130.1 & 34
\end{tabular}


Goats of the single group (treated with FF) and goats of the combined group (treated with FF and DOX) were euthanized as previously described at $0.5(n=4), 1(n=4), 3(n=4)$, $7(n=4), 14(n=4)$, and 21 days $(n=4)$ after the last dose of $20 \mathrm{mg} \mathrm{FF} / \mathrm{kg}$ bw (single group) and after the last dose of $20 \mathrm{mg} \mathrm{FF} / \mathrm{kg}$ bw plus $10 \mathrm{mg}$ DOX/kg bw (combined group). Goats were immediately exsanguinated, and tissue specimens of liver, kidney and muscle were collected separately. Each of the tissue specimens was carefully weighed and stored frozen at $-20^{\circ} \mathrm{C}$ until assayed for concentrations of FF and FFA.

\section{Gene Expression of CYP3A24 in Goats}

Real-time quantitative polymerase chain reaction (qPCR) was used to detect the expression of CYP3A24 in treated goats. Total
RNA was extracted from goat liver by using the Trizol method. The concentration and purity of RNA was detected by Q3000 (Thermo, USA). The extracted RNA was reverse transcribed into cDNA. Goat-specific primers have shown as Table 3. The reaction procedure is: stage $1,95^{\circ} \mathrm{C}$ for $30 \mathrm{~s}$; stage 2,40 cycles at $95^{\circ} \mathrm{C}$ for $3 \mathrm{~s}, 60^{\circ} \mathrm{C}$ for $10 \mathrm{~s}$ and $72^{\circ} \mathrm{C}$ for $20 \mathrm{~s}$; stage 3 , melt phase. The data were analyzed by the $2^{\Delta \Delta \mathrm{Ct}}$ method.

\section{Sample Pre-treatment and Residue Detection}

The method of FF and FFA pre-processing in the target tissues was as follows: Tissue samples weighing $1.00 \pm 0.01 \mathrm{~g}$ were placed in a $10 \mathrm{~mL}$ centrifuge tube, then $5 \mathrm{~mL} 2 \%$ ammoniated ethyl acetate was added, and the tube was vortexed, sonicated

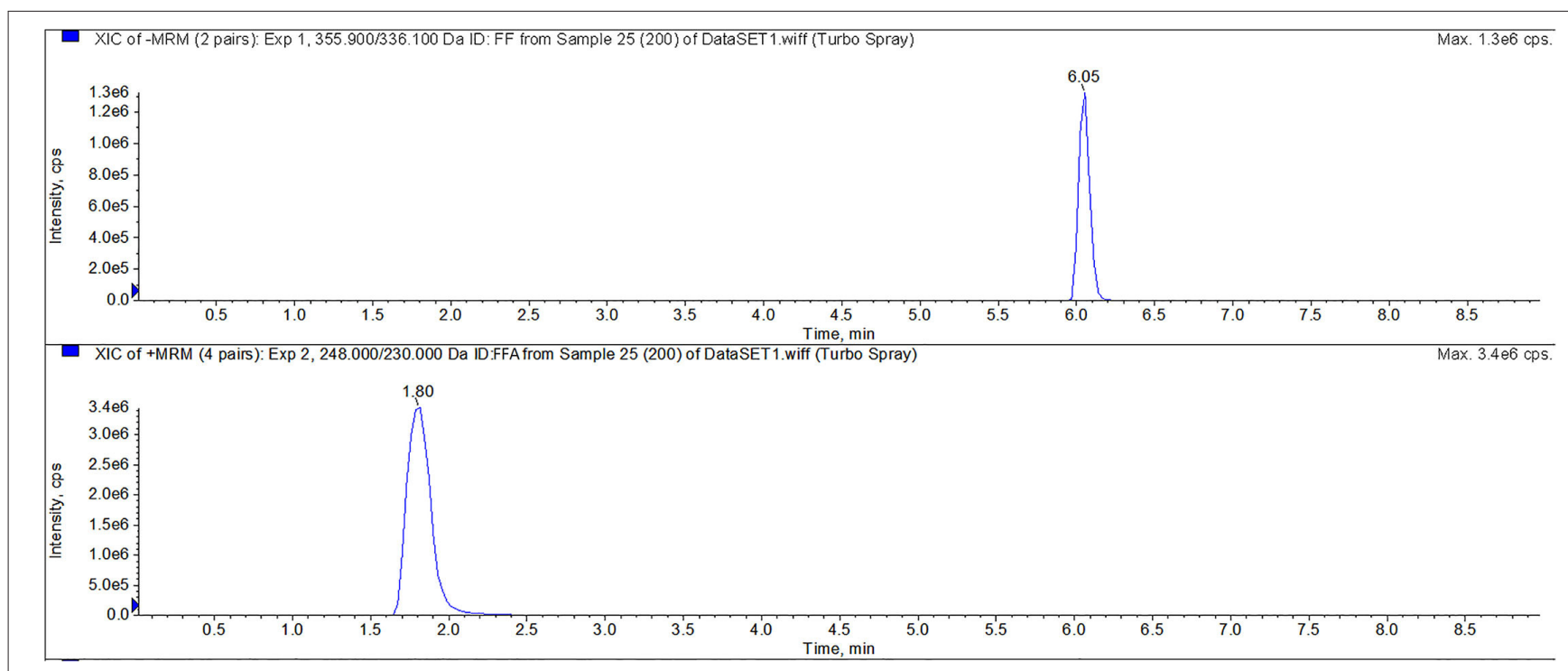

FIGURE 1 | LC-MS/MS method for detecting FF, and FFA. The peak times of FFA and FF were 1.80 and 6.05 min, respectively.

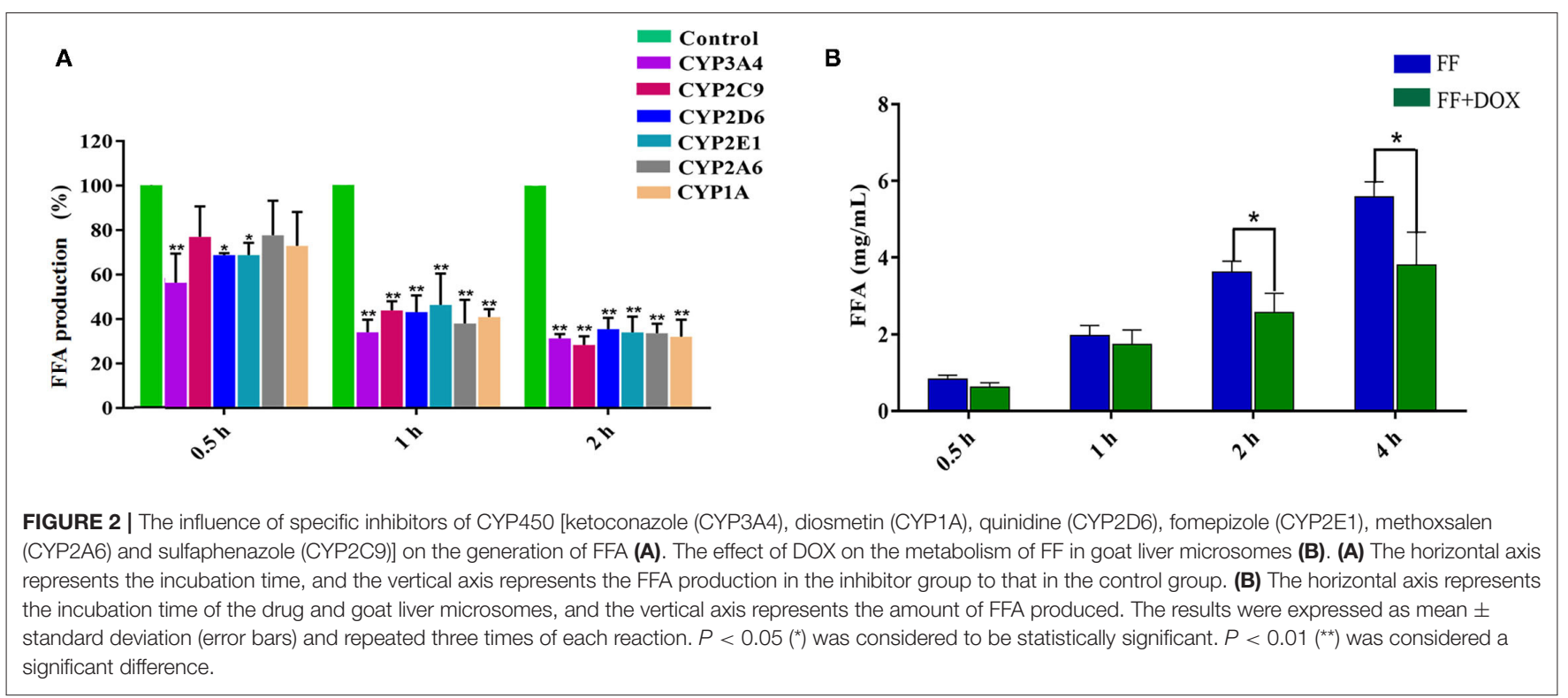


and centrifuged. The above steps were repeated, and the supernatants were pooled and dried under a stream of nitrogen. The residue was reconstituted in 5\% acetic acid in water, vortexed and passed through an MCX solid-phase extraction column (the order of the column was methanol, water, sample, $5 \%$ acetic acid water and $8 \%$ ammoniated ethyl acetate), then the eluate was dried under nitrogen, re-dissolved in $2 \mathrm{~mL}$ of degreased $\mathrm{n}$-hexane, passed through a $0.22 \mu \mathrm{m}$ filter membrane and subjected to LC-MS/MS (AB SCIEX API5000, USA) analysis.

For FF and FFA, chromatographic separation was performed using a Thermo Scientific Hypersil Gold C18 column (150 $\times 2.1 \mathrm{~mm}, 5 \mu \mathrm{m}$ particles). Mobile phase A was $0.1 \%$ formic acid in water, and mobile phase $\mathrm{B}$ was acetonitrile. The mass spectrometric parameters for FF and FFA was shown in Table 4. The flow rate was $0.3 \mathrm{~mL} / \mathrm{min}$ with a linear gradient under the following conditions: $0-1 \mathrm{~min} 10 \% \mathrm{~B}, 1-5 \mathrm{~min} 10-70 \% \mathrm{~B}$, 5-6 min $70 \% \mathrm{~B}$, 6-6.1 min $70-10 \% \mathrm{~B}$, and $6.10-9.00 \mathrm{~min} 10 \%$ B. All calibration curves exhibited a correlation co-efficient ( $r$ ) exceeding 0.99 across the concentration range. All interassay coefficients of variation in each tissue were within $9.93 \%$, the intra-assay coefficients of variation in each tissue were within $11.08 \%$, and the recovery rates in each tissue were between 70.62 and $113.55 \%$. The LC-MS/MS results of FF and FFA standard products showed that the method had good specificity. For FF and FFA, the LOQ of the analysis was $10 \mu \mathrm{g} / \mathrm{kg}$, and the LOD of the analysis was $2 \mu \mathrm{g} / \mathrm{kg}$. The peak times of FFA and FF were 1.80 and 6.05, respectively (Figure 1).

\section{Analysis of Experimental Data}

Significance analysis between different groups using one-way ANOVA with SPSS Statistics, version 18.0 (SPSS Inc., Chicago, IL). $0.01<P<0.05$ indicates a significant difference, marked with ${ }^{*} ; P<0.01$ indicates a very significant difference, marked with $* *$.

The withdrawal period was estimated by linear regression analysis of log-transformed tissue concentrations and was determined at the time when the 95\% upper oneside tolerance limit was below the MRL with $95 \%$ confidence (22).

\section{RESULTS}

\section{CYP3A24 May Be the Main Metabolic Enzyme of FF in Breed Goat Liver Microsomes}

The influence of CYP450-specific inhibitors on the production of FFA is shown in Figure 2A. Compared with the inhibitorfree group (control group), the production of FFA decreased at all times after the addition of CYP450 inhibitors. The inhibition percentage of FFA production was as follows: at $0.5 \mathrm{~h}$ of incubation, the order was CYP3A4 (43.66\%) > CYP2E1 (31.20\%) > CYP2D6 (31.19\%) > CYP1A $(27.13 \%)$ $>$ CYP2C9 (23.01\%) > CYP2A6 (22.28\%) inhibitors. After $1 \mathrm{~h}$ of incubation, the order of influence on FF metabolism was: CYP3A4 (65.94\%) > CYP2A6 (62.02\%) > CYP1A $(59.13 \%)>$ CYP2D6 $(56.90 \%)>$ CYP2C9 $(56.16 \%)>$ CYP2E1 (53.71\%) inhibitors. After $2 \mathrm{~h}$ of incubation, the order of

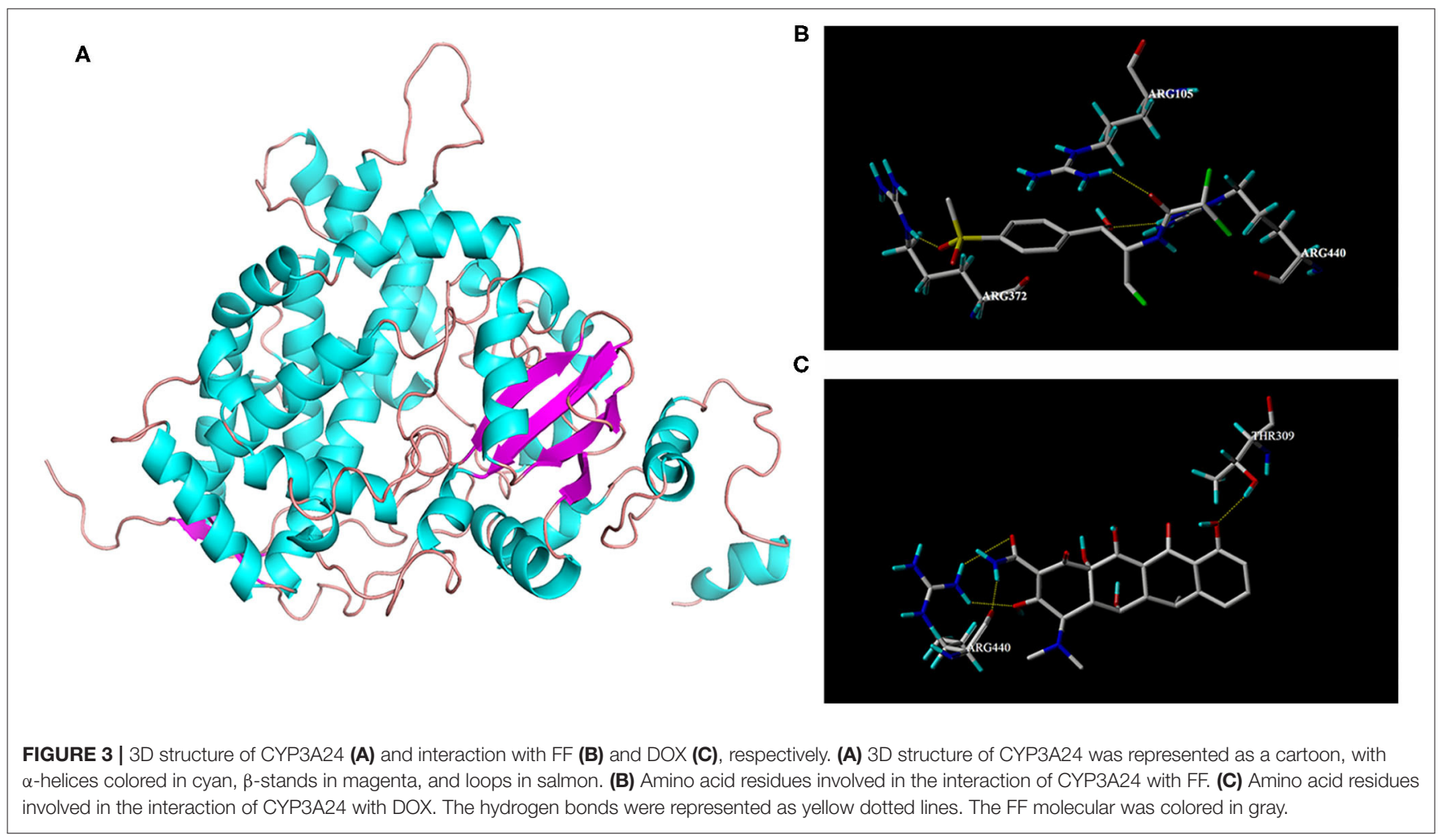


influence on FF metabolism was: CYP2C9 (71.70\%) > CYP3A4 $(68.73 \%)>$ CYP1A $(67.95 \%)>$ CYP2A6 (66.44\%) > CYP2E $(66.06 \%)>$ CYP2D6 (64.62\%) inhibitors. In general, the result showed that $\mathrm{CYP} 3 \mathrm{~A}$ is the most critical enzyme in FF metabolism.

\section{In Breed Goat Liver Microsomes, DOX Slows Down FF Metabolism}

The result is represented in Figure 2B. After 0.5 and $1 \mathrm{~h}$ incubations, there was no significant difference in the amount of FFA produced between the single group (FF) and the combined group (FF + DOX). After 2 and $4 \mathrm{~h}$ incubations, the production of FFA in the single group was significantly higher (41.4 and 46.5\%, respectively), than that of the combined group. It is speculated that FF and DOX interact in liver microsomes, slowing down FF metabolism.

\section{Homologous Modeling Molecular Docking}

The protein structure of goat CYP3A24 was modeled using CYP3A4 as a template, which is displayed by the visualization software Pymol, as shown in Figure 3A. In order to better explore the mechanism by which DOX affects FF metabolism, FF and DOX were molecularly docked with CYP3A24, and the docking results are shown in Figures 3B,C. For FF, three hydrogen bonds were formed between the CYP3A24 protein and FF in the active pocket. Among the hydrogen bonds forming AAs, one hydrogen bond was, respectively, formed with $\mathrm{R} 105, \mathrm{R} 372, \mathrm{R} 440$. The key amino acid residues in CYP3A24 that play a role in FF metabolism may be R105, R372, and R440. For DOX, four hydrogen bonds were formed between the CYP3A24 protein and DOX in the active pocket. Among the hydrogen bonds forming AAs, in which one hydrogen bond was formed with T309, and three hydrogen bonds were formed with R440. The amino acid residues in CYP3A24 that

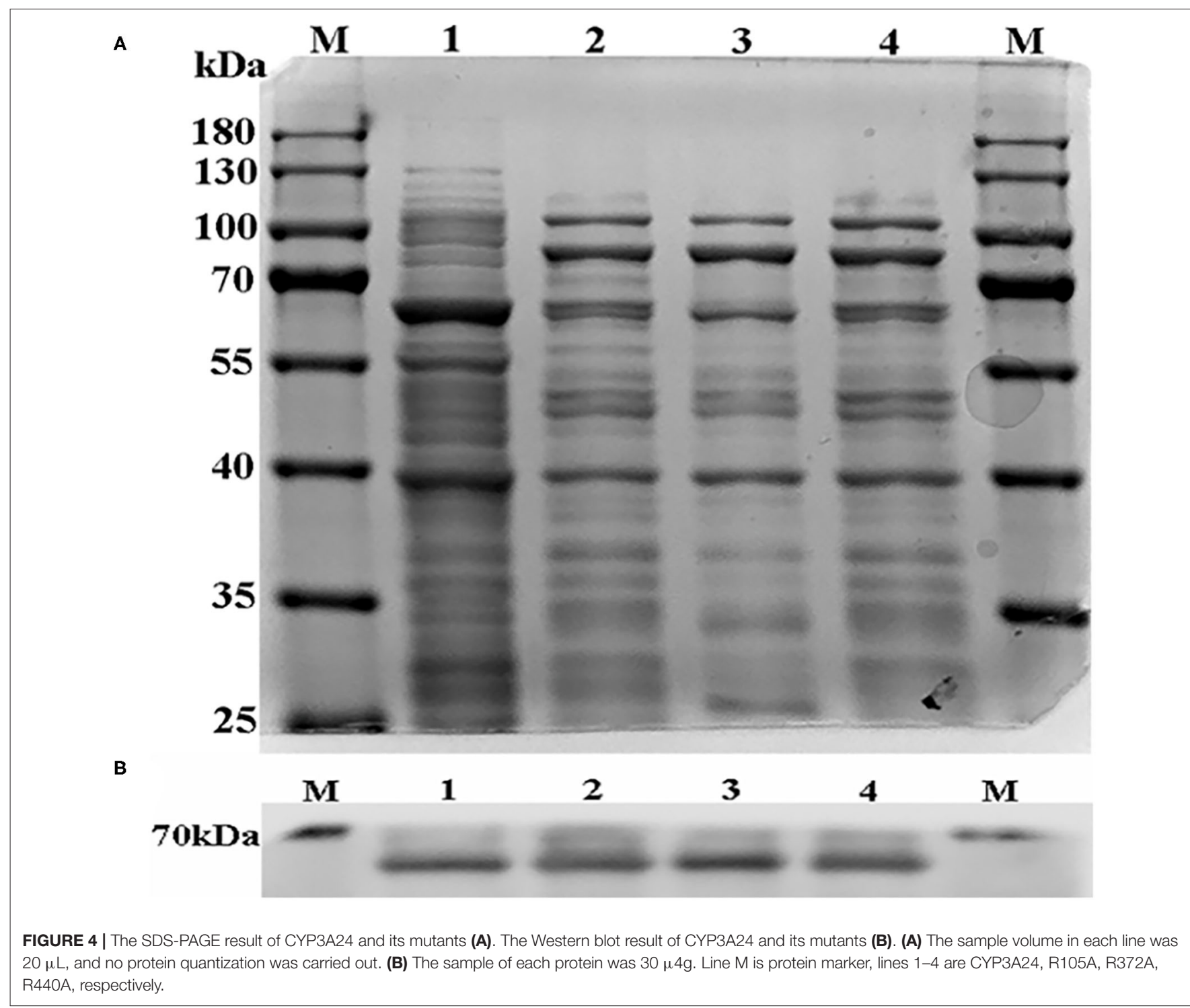


interact with DOX may be T309 and R440. It is speculated that the interaction between FF and DOX may be related to R440.

\section{Protein Expression of CYP3A24 and Its Mutants}

The $\mathrm{R}$ (arginine) side chain is positively charged and forms ionic interactions with negatively charged groups. A (alanine) has a non-polar side chain, which is non-reactive and can eliminate the ionic interaction (23). For this reason, we mutated $\mathrm{R}$ to $\mathrm{A}$. According to the website http:// web.expasy.org/compute_pi/, the protein molecular weight of CYP3A24 is predicted to be about $58 \mathrm{kDa}$. As shown in Figure 4, the results of SDS-PAGE and Western blot show that the molecular weight of the protein is consistent with the prediction.

\section{CYP3A24 Enzyme and Its a Mutant Protein Had Good Activity}

TS can be metabolized into $6 \beta$-OHTS by CYP3A enzyme. The peak time of $6 \beta$-OHTS was about $4.95 \mathrm{~min}$. The results show that CYP3A24, R105A, R372A, and R440A could metabolize TS, and all the proteins were active (Figure 5).

\section{R440A May Be a Key Amino Acid Through Which DOX Affects the FF Metabolism}

According to Figure 6 when incubated with CYP3A24, the addition of DOX reduced the production of FFA in $17.8 \%$, that is, the metabolism of FF was inhibited. The key amino acid sequence that reduced FF metabolism was: R440A (65.8\%) and R372A (32.9\%). R440A is a key amino acid for CYP3A24 enzyme to metabolize FF. Since R440A is the common site in the docking result of FF and DOX, it is speculated that the reason why DOX

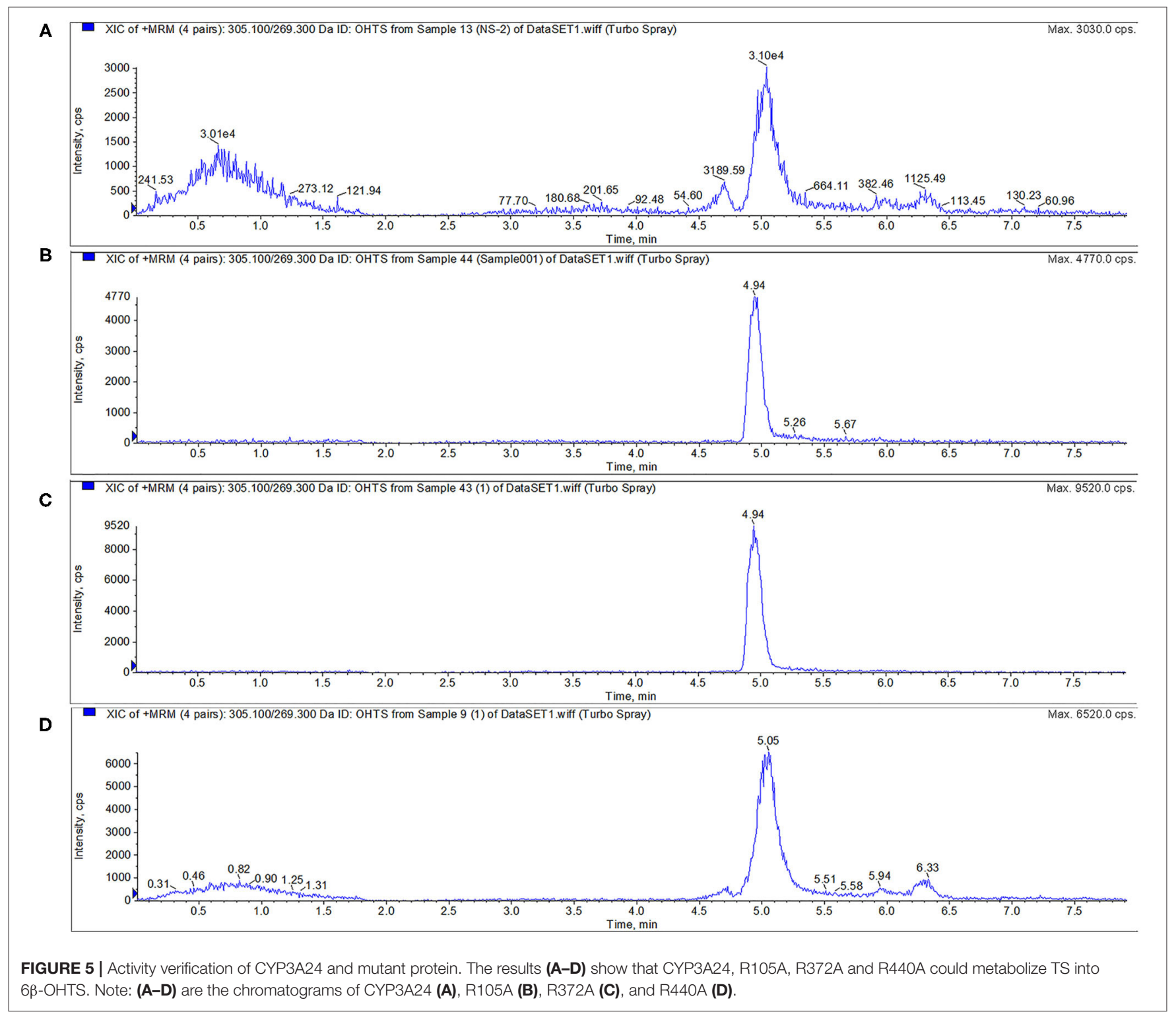




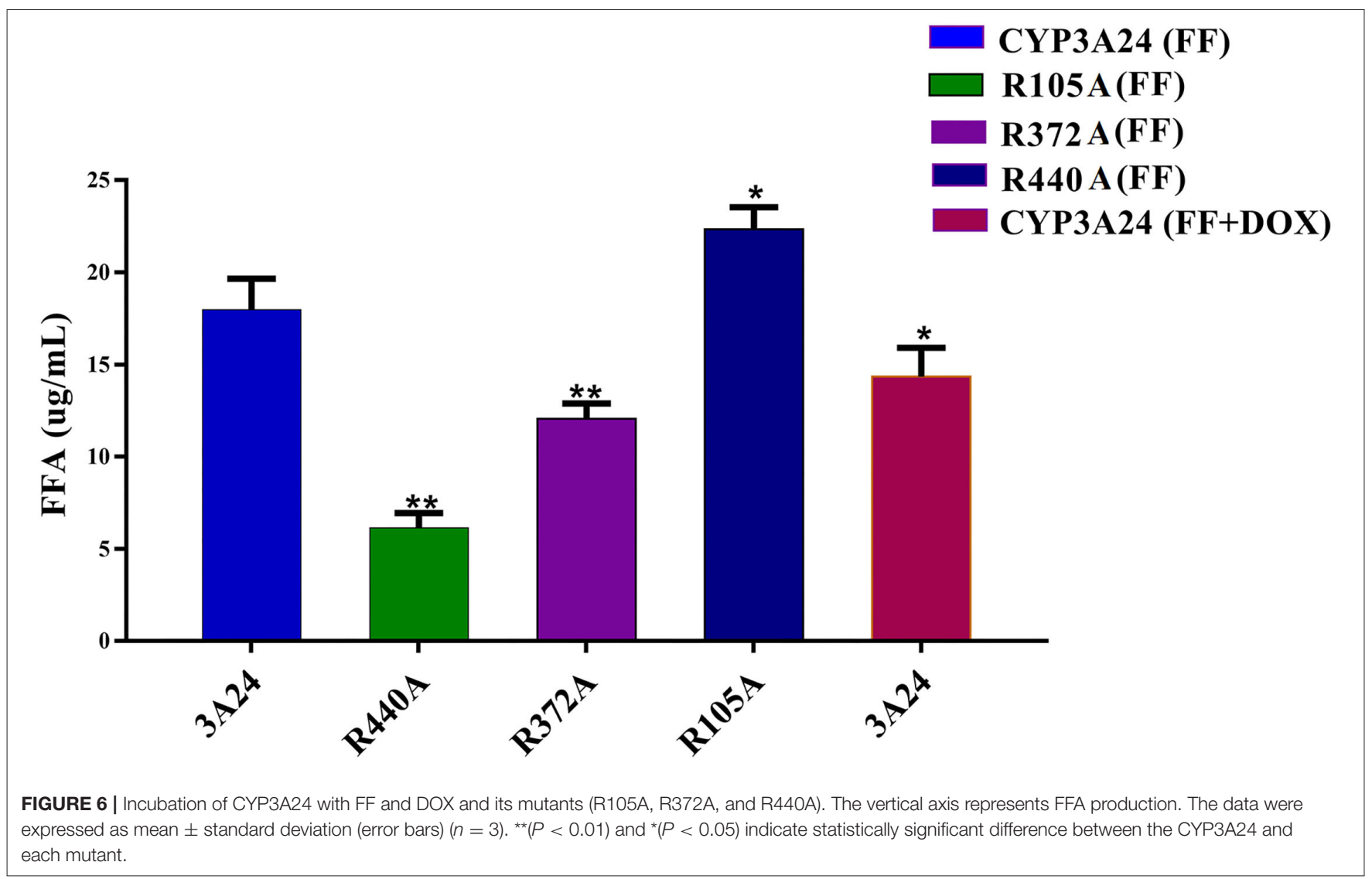

inhibits FF metabolism is that DOX competes with R440 for the CYP3A24 enzyme.

\section{The Effect of DOX and FF on CYP3A24 Gene Expression in Goats}

The concentration and purity of RNA extracted from goat liver were good. The A260/280 ratio of all RNA extracted was between 1.8 and 2.0 , and the concentration was about $2,000 \mathrm{ng} / \mu \mathrm{L}$. The effect of single administration of FF and co-administration of FF and DOX on the expression level of the CYP3A24 gene in goats is shown in Figure 7.

When FF was stopped for 1 and 3 days, the gene expression level of CYP3A24 enzyme was up-regulated in the single groups, about 2.3 and 3 -fold, respectively compared to control.

When FF + DOX was stopped for 1 and 3 days, the upregulation of CYP3A24 enzyme gene expression in the combined groups decreased significantly compared to single groups, about 0.7 and 1-fold, respectively. This indicates that DOX can inhibit up-regulation of the CYP3A24 gene.

\section{Tissue Residue Depletion}

Residues of FF and its metabolite FFA in tissue specimens after intramuscular administration of FF $(20 \mathrm{mg} / \mathrm{kg}$ bw, at $48 \mathrm{~h}$ intervals, twice in total) in single group and after FF $(20 \mathrm{mg} / \mathrm{kg}$ bw, at $48 \mathrm{~h}$ intervals, twice in total) plus DOX $(10 \mathrm{mg} / \mathrm{kg}$ bw, once a day for 3 days) in combined group, were determined. The tissue concentration-time profiles are presented in Table 5 for liver, kidney, and muscle from single and combined groups at $0.5,1,3,7,14$, and 21 days after administration of the final dose of FF (single group) and a after administration of the final dose of FF plus DOX (combined group).

\section{Withdrawal Period Estimation}

Linear regression analysis of the logarithmic transformed data can be considered for the calculation of the withdrawal periods. Using this approach, the withdrawal period was determined as the period when the one-sided, 95\% upper tolerance limit of the regression line with 95\% confidence level was below the MRL (22). Using this approach and considering the marker residue for the MRL (the sum of FF and its metabolite FFA) recommended by de EU, the withdrawal period for FF was calculated for single group and combined group in kidney (tissue which showed slower residue depletion). After intramuscular administration of $\mathrm{FF}(20 \mathrm{mg} / \mathrm{kg}$ bw, at $48 \mathrm{~h}$ intervals, twice in total) in single group and after FF $(20 \mathrm{mg} / \mathrm{kg} \mathrm{bw}$, at $48 \mathrm{~h}$ intervals, twice in total) plus DOX (10 mg/kg bw, once a day for 3 days) in combined group, the withdrawal periods were 17.18 days and 18.61 days, respectively (Figures 8A,B). When DOX is used in combination with FF, the withdrawal period of FF in the kidney was extended by 1 day. 


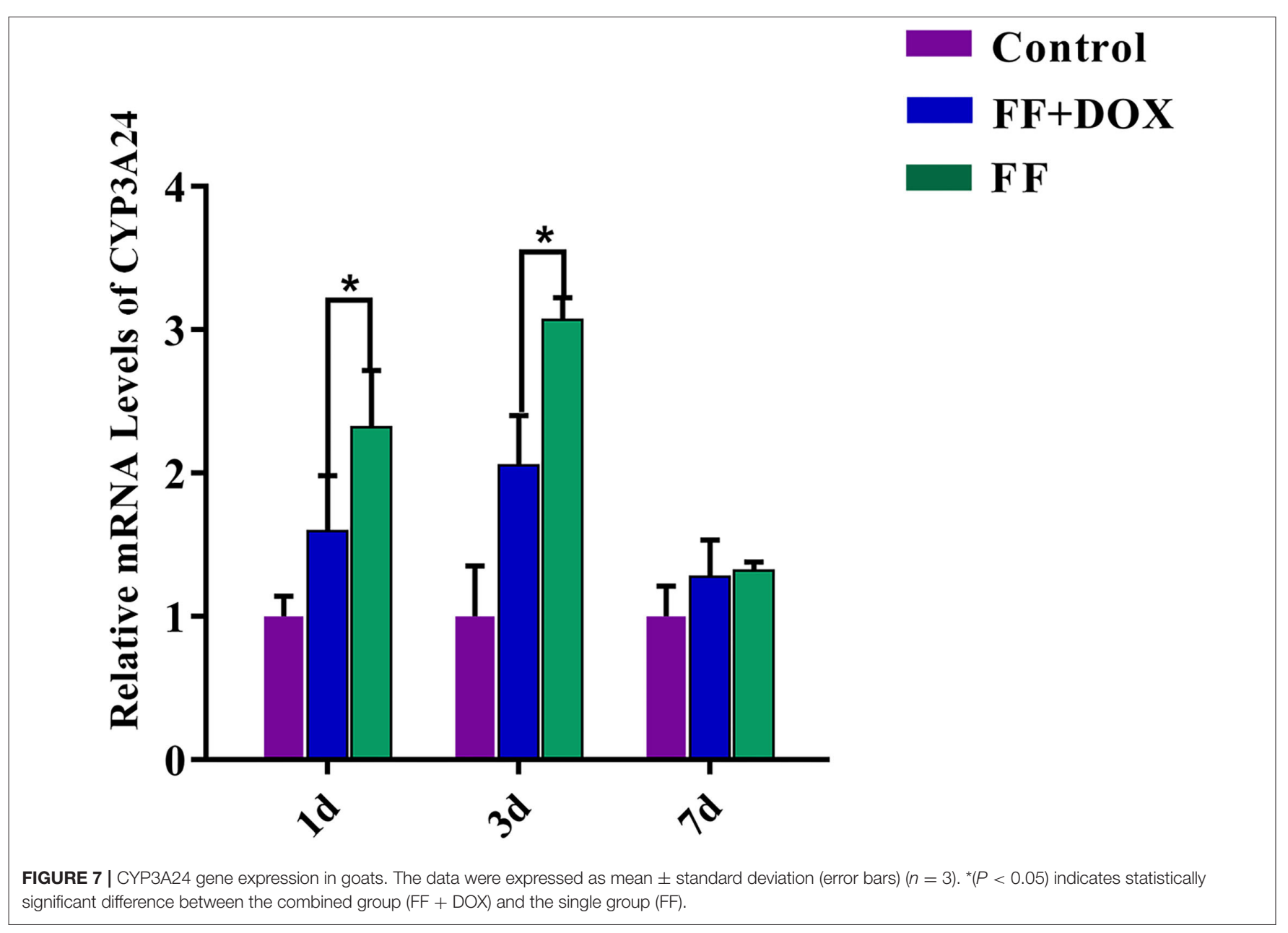

\section{DISCUSSION}

In veterinary medicine, drugs are often used in combination; improving efficacy is the primary factor in drug combination. However, DDI often produces some adverse effects (24). Metabolism is a key factor affecting DDI, and CYP450 enzymes are a key factor affecting metabolism (25). The inhibition of CYP enzymes may cause the accumulation of drugs in the body, resulting in toxicity or prolonging the drug withdrawal period (26). Therefore, it is necessary to study combinations of drugs from the perspective of enzymes. FF and DOX are often used together in clinical treatment. Previous studies have shown that the metabolism of FF in rabbits and chickens is affected by CYP3A $(11,12)$, and DOX has the effect of inhibiting CYP3A (13). Therefore, this research studies the combined use of DOX and FF from the perspective of liver microsomes and recombinant metabolic enzymes. Moreover, in vivo experiments were also conducted to verify the effects of the two antibacterial on metabolism, and to recommend a withdrawal period, so as to better guide clinical medication.

In vitro goat liver microsome experiments showed that CYP3A is the most important metabolic enzyme that affects the metabolism of FF (Figure 2A). This is consistent with studies in rabbit and chicken $(11,12)$. The addition of DOX will slow down the metabolism of FF (Figure 2B). If the functionally homologous proteins have sequence homology $>30 \%$, then a known protein crystal structure can be used as a template to establish a highly accurate target protein structure model. The sequence homology between goat CYP3A24 and human CYP3A4 enzymes reached $76.5 \%$. So we used human CYP3A4 as a template for homology modeling and obtained CYP3A24 (Figure 3A). Then we have molecularly docked FF and DOX with CYP3A24 enzyme and screened out the possible key amino acids for FF metabolism as R105, R372, and R440 (Figure 3B), and T309 and R440 as possible key amino acids for DOX metabolism (Figure 3C). Site-directed mutagenesis is often used to study the impact of specific sites on the overall structure (27). Therefore, in this experiment, the three amino acids (R105, R372, and R440) were mutated to R105A, R372A, and R440A. The mutated protein was incubated with the drug to determine that R440A may be the key amino acid through which DOX affects FF (Figure 6). Combined with previous research on the interaction between R440 and CYP2D6, R440 is very likely to be the main site of CYP2D6 binding to reductase (28). This research suggests that 
TABLE 5 | Tissue concentrations of FF and FFA for goats treated intramuscularly with FF (single group) and for goats treated with FF plus DOX (combined group).

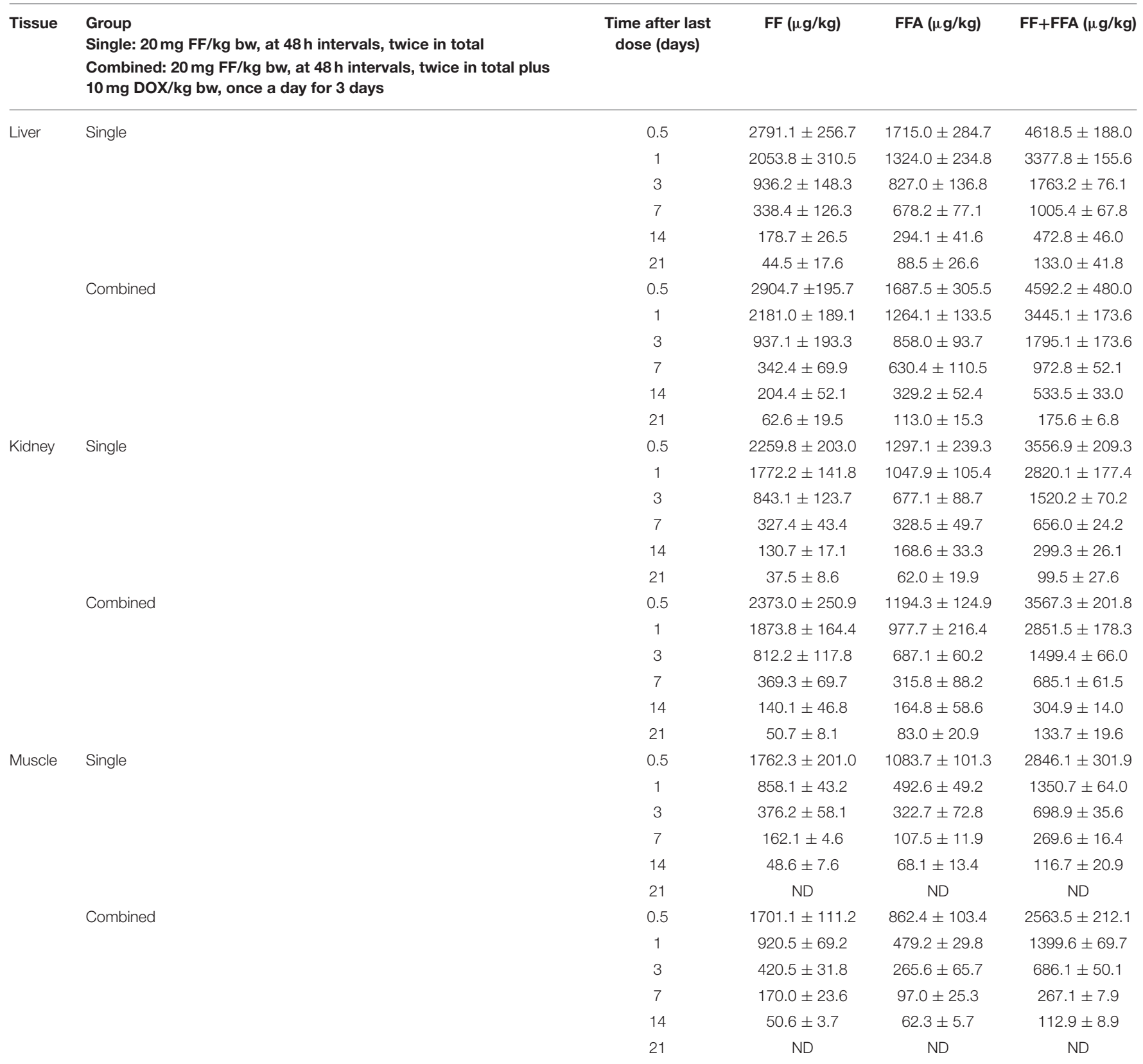

Each value is the mean $\pm S D$ for 4 goats.

R440 plays an important role in the electron transfer and binding between CYP3A24 and its reductase. When it is destroyed, the metabolism of FF and DOX will be affected; when FF is used in combination with DOX, the DOX will compete for R440 on the CYP3A24 enzyme, which will slow down FF metabolism.

Notably, the effect of DOX on FF metabolism was significant. In vivo experiments have shown that DOX can inhibit the upregulation of CYP3A24 gene expression caused by FF (Figure 7). Residue depletion studies in goats showed that the addition of DOX would slow down the elimination half-life of FF and FFA (Table 3). EMA withdrawal-period calculation-program WT1.4 software (22) was used to analyse the withdrawal period of FF from goat target tissue concentrations of FF and FFA (Figure 8). Notably, the effect of DOX on FF metabolism was significant. The combination of FF and DOX caused a prolonged withdrawal period of FF in the kidney; the withdrawal period of FF in the kidney was extended by 1 day. In addition, the kidney toxicity of FF has been confirmed in animals. FF can up-regulate the expression of pro-apoptotic factors and accelerate the abnormal apoptosis of renal cells (29). Therefore, whether the effect of DOX on FF metabolism in the kidney will lead to the enhancement of this toxic effect remains to be studied. 
A

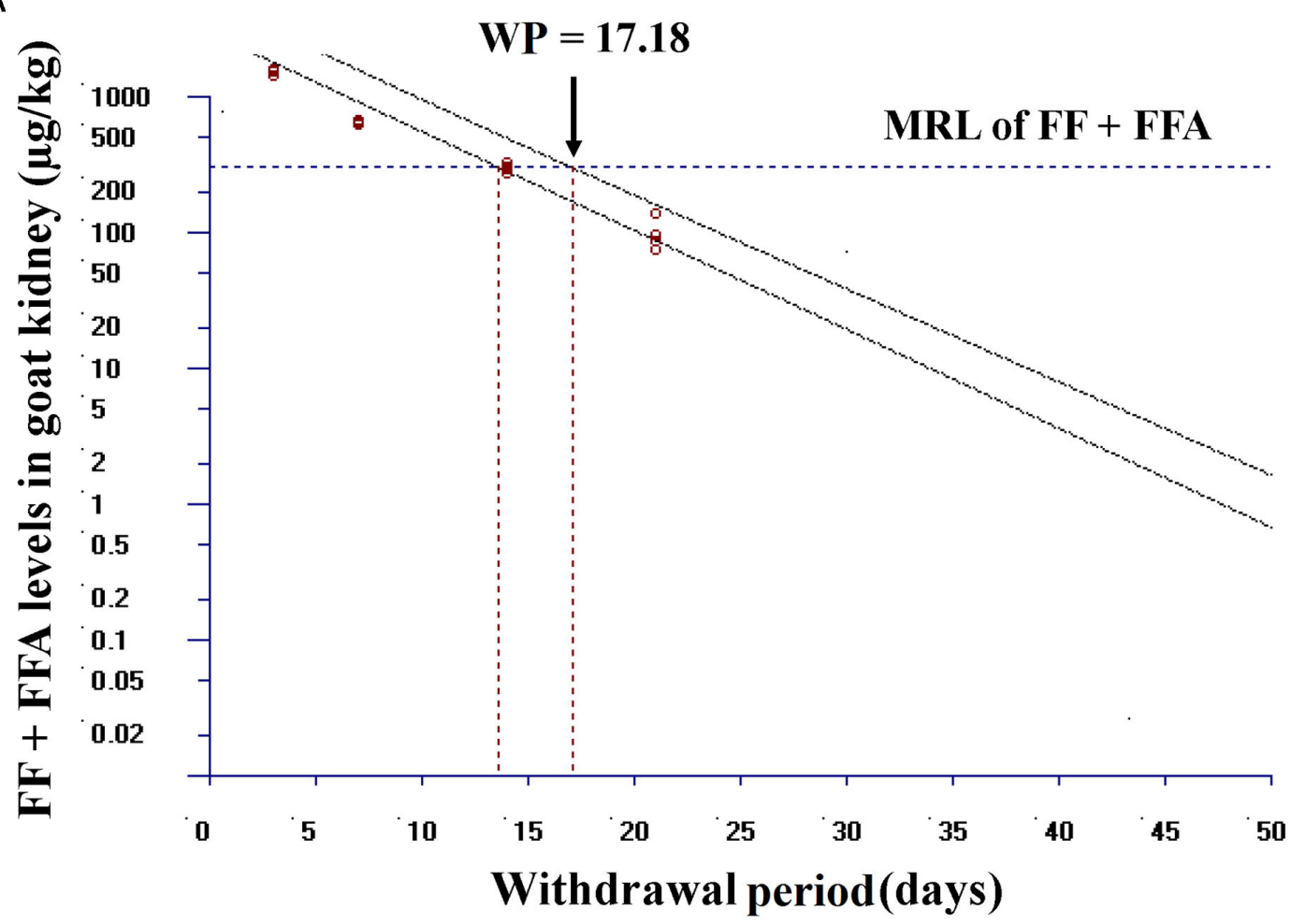

B

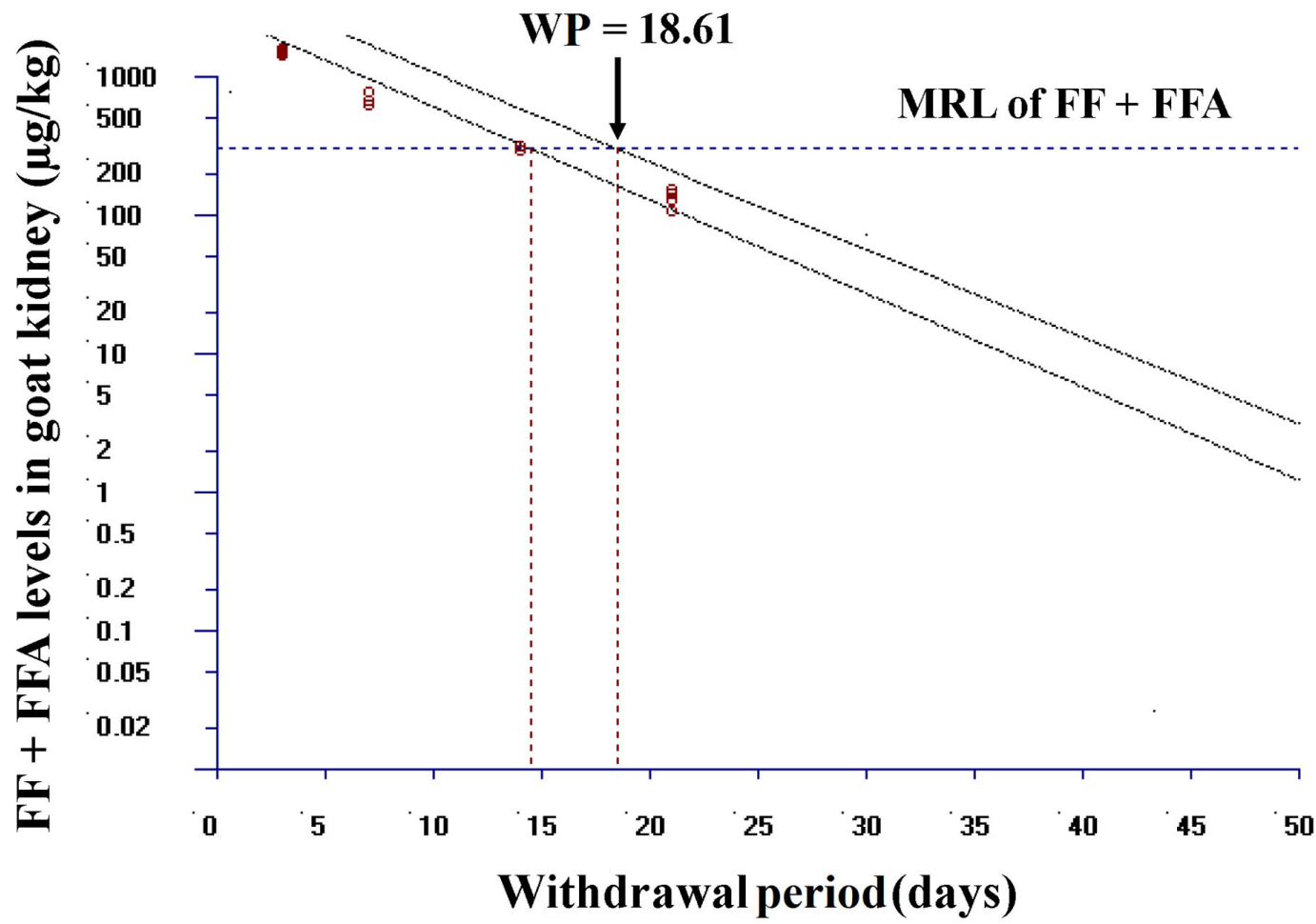

FIGURE 8 | Plot of the withdrawal period calculation for FF in goat kidney at the time when the one-sided 95\% upper tolerance limit is below the EU MRL for FF (300 $\mu \mathrm{g} / \mathrm{kg}$ ). (A) In single group, after intramuscular administration of FF (20 mg FF/ kg bw, at $48 \mathrm{~h}$ intervals, twice in total) and (B) in combined group, after intramuscular administration of FF (20 mg FF/kg bw, at $48 \mathrm{~h}$ intervals, twice in total) plus DOX (10 mg DOX/kg bw, once a day for 3 days). Residue marker is the sum of florfenicol (FF) and its metabolite florfenicol-amine (FFA). 


\section{DATA AVAILABILITY STATEMENT}

The raw data supporting the conclusions of this article will be made available by the authors, without undue reservation.

\section{ETHICS STATEMENT}

The animal study was reviewed and approved by Ethics Committee of Veterinary College of Huazhong Agricultural University (HZAU).

\section{AUTHOR CONTRIBUTIONS}

$\mathrm{XW}$ and YY: software, validation, formal analysis, investigation, data curation, visualization, and writing - original draft. M-AM,

\section{REFERENCES}

1. Anadón A, Martínez MA, Martínez M, Ríos A, Caballero V, Ares I, et al. Plasma and tissue depletion of florfenicol and florfenicol-amine in chickens. $J$ Agric Food Chem. (2008) 56:11049-56. doi: 10.1021/jf802138y

2. Berge ACB, Sischo WM, Craigmill AL. Antimicrobial susceptibility patterns of respiratory tract pathogens from sheep and goats. J Am Vet Med Assoc. (2006) 229:1279-81. doi: 10.2460/javma.229.8.1279

3. Shah JM, Qureshi TA, Shah T, Shah QA, Arain MA, Bhutto ZA, et al. Impact of therapeutic and high doses of florfenicol on kidney and liver functional indicators in goat. Vet World. (2016) 9:1135-40. doi: 10.14202/vetworld.2016.1135-1140

4. Wei CF, Shien JH, Chang SK, Chou CC. Florfenicol as a modulator enhancing antimicrobial activity: example using combination with thiamphenicol against Pasteurella multocida. Front Microbiol. (2016) 7:389. doi: 10.3389/fmicb.2016.00389

5. EU (European Union). Commission Regulation No 37/2010 of 22 December 2009 on pharmacologically active substances and their classification regarding maximum residue limits in foodstuffs of animal origin. Official J Eur Union. L 15/1. (2010). Available online at: https://ec.europa.eu/health/sites/default/ files/files/eudralex/vol-5/reg_2010_37/reg_2010_37_en.pdf

6. Anadón A, Martínez-Larrañaga MR, Diaz MJ, Bringas P, Fernandez MC, Fernandez-Cruz ML, et al. Pharmacokinetics of doxycycline in broiler chickens. Avian Pathol. (1994) 23:79-90. doi: 10.1080/030794594084 18976

7. Anadón A, Martínez-Larrañaga MA. Residues of antimicrobial drugs and feed additives in animal products: regulatory aspects. Livest Prod Sci. (1999) 59:183-98. doi: 10.1016/S0301-6226(99)00026-3

8. Rattanapanadda P, Kuo HC, Vickroy TW, Sung CH, Rairat T, Lin TL, et al. In vitro and in vivo synergistic effects of florfenicol and thiamphenicol in combination against swine Actinobacillus pleuropneumoniae and Pasteurella multocida. Front Microbiol. (2019) 10:2430. doi: 10.3389/fmicb.2019. 02430

9. Karbownik A, Miedziaszczyk M, Grabowski T, Stanisławiak-Rudowicz J, Jazwiec R, Wolc A, et al. In vivo assessment of potential for UGTinhibition-based drug-drug interaction between sorafenib and tapentadol. Biomed Pharmacother. (2020) 130:110530. doi: 10.1016/j.biopha.2020.1 10530

10. Shoombuatong W, Prathipati P, Prachayasittikul V, Schaduangrat N, Malik AA, Pratiwi R, et al. Towards predicting the cytochrome P450 modulation: from QSAR to proteochemometric modeling. Curr Drug Metab. (2017) 18:540-55. doi: 10.2174/1389200218666170320121932

11. Liu N, Guo M, Mo F, Sun YH, Yuan Z, Cao LH, et al. Involvement of P-glycoprotein and cytochrome P450 3A in the metabolism of florfenicol of rabbits. J Vet Pharmacol Ther. (2012) 35:202-5. doi: 10.1111/j.1365-2885.2011.01310.x
MM, BL-T, M-RM-L, and IA: software, validation, formal analysis, investigation, data curation, visualization, writingoriginal draft, and writing-review and editing. XW and AA: conceptualization, methodology, resources, investigation, writing - original draft, writing - review and editing, supervision, and project administration. All authors contributed to the article and approved the submitted version.

\section{FUNDING}

This work was supported by the National Key Research and Development Program of China (2018YFC1603005), the Fundamental Research Funds for the Central Universities (2662020DKPY020), and Project Ref. PID 2020-115979RR-C33 from the Ministerio de Ciencia e Innovación, Spain.

12. Wang GY, Zheng HH, Zhang KY, Yang F, Kong T, Zhou B, et al. The roles of cytochrome P450 and P-glycoprotein in the pharmacokinetics of florfenicol in chickens. Iran J Vet Res. (2018) 19:9-14.

13. Zhao XJ, Ishizaki $\mathrm{T}$. The in vitro hepatic metabolism of quinine in mice, rats and dogs: comparison with human liver microsomes. J Pharmacol Exp Ther. (1997) 283:1168-76.

14. Ali BH, Al-Qarawi AA, Hashaad M. Comparative plasma pharmacokinetics and tolerance of florfenicol following intramuscular and intravenous administration to camels, sheep and goats. Vet Res Commun. (2003) 27:47583. doi: 10.1023/A:1025741724701

15. Naeem MA, Karrow NA, Ashraf MM, Wu J. Kinetic interaction between albendazole and florfenicol in healthy adult female Beetal goats. J Biol Regul Homeost Agents. (2019) 33:835-41.

16. EU (European Union). Regulation (EU) 2019/6 of the European Parliament and of the Council of 11 December 2018 on Veterinary Medicinal Products and Repealing Directive 2001/82/EC. L 4/43. (2019). Available online at: https://eur-lex.europa.eu/legal-content/EN/TXT/PDF/?uri=CELEX: 32019R0006\&from =es (accessed July 15, 2021).

17. Smith JS, Mochel JP, Borts DJ, Griffith RW. Effects of experimentally induced respiratory disease on the pharmacokinetics and tissue residues of tulathromycin in meat goats. J Vet Pharmacol Ther. (2019) 42:420-9. doi: 10.1111/jvp.12764

18. Ning J, Ahmed S, Cheng G, Chen T, Wang Y, Peng D, et al. Analysis of the stability and affinity of BlaR-CTD protein to $\beta$-lactam antibiotics based on docking and mutagenesis studies. J Biol Eng. (2019) 13:27. doi: 10.1186/s13036-019-0157-4

19. Silva D, Santos G, Barroca M, Collins T. Inverse PCR for point mutation introduction. Methods Mol Biol. (2017) 1620:87-100. doi: 10.1007/978-1-4939-7060-5_5

20. Shahrisa A, Nikkhah M, Shirzad H, Behzadi R, Sadeghizadeh M. Enhancing catecholase activity of a recombinant human tyrosinase through multiple strategies. Iran J Biotechnol. (2020) 18:e2310. doi: 10.30498/ijb.2020.137293.2310

21. Mustapić DS, Debeljak Ž, Maleš Ž, Bojic M. The inhibitory effect of flavonoid aglycones on the metabolic activity of CYP3A4 enzyme. Molecules. (2018) 23:2553. doi: $10.3390 /$ molecules23102553

22. EMA (European Medicines Agency). Guideline on Determination of Withdrawal Periods for Edible Tissues. EMA/CVMP/SWP/735325/2012, Committee for Medicinal Products for Veterinary Use (CVMP). Canary Wharf, London, U.K. (2018). p. 1-36. Available online at: https://www. ema.europa.eu/en/documents/scientific-guideline/ guideline-determinationwithdrawal-periods-edible-tissues-revision-1_en.pdf

23. Cheng G, Liu C, Wang X, Ma H, Pan Y, Huang L, et al. Structure-function analysis of porcine cytochrome P450 3A29 in the hydroxylation of T-2 toxin as revealed by docking and mutagenesis studies. PLOS ONE. (2014) 9:e106769. doi: 10.1371/journal.pone.0106769 
24. Patrick MT, Bardhi R, Raja K, He K, Tsoi LC. Advancement in predicting interactions between drugs used to treat psoriasis and its comorbidities by integrating molecular and clinical resources. J Am Med Inform Assoc. (2021) 28:1159-67. doi: 10.1093/jamia/ocaa335

25. Lee J, Yang Y, Zhang X, Fan J, Grimstein M, Zhu H, et al. Usage of in vitro metabolism data for drug-drug interaction in physiologically based pharmacokinetic analysis submissions to the US food and drug administration. J Clin Pharmacol. (2021) 61:782-8. doi: 10.1002/jcph.1819

26. Hurtado FK, de Braud F, De Castro Carpeño J, de Migel Luken MJ, Wang D, Scott J, et al. Effect of ceritinib on the pharmacokinetics of coadministered CYP3A and 2C9 substrates: a phase I, multicenter, drug-drug interaction study in patients with ALK + advanced tumors. Cancer Chemother Pharmacol. (2021) 87:475-86. doi: 10.1007/s00280-02004180-3

27. Wu J, Zhu S, Wu Y, Jiang $\mathrm{T}$, Wang L, Jiang J, et al. Multiple $\mathrm{CH} / \pi$ interactions maintain the binding of aflatoxin B1 in the active cavity of human cytochrome P450 1A2. Toxins. (2019) 11:158. doi: 10.3390/toxins110 30158

28. Allorge D, Bréant D, Harlow J, Chowdry J, Lo-Guidice JM, Chevalier D. et al. Functional analysis of CYP2D631 variant: homology modeling suggests possible disruption of redox partner interaction by Arg440His substitution. Proteins. (2005) 59:339-46. doi: 10.1002/prot. 20399
29. Wang X, Han C, Cui Y, Li S, Jin G, Shi W, et al. Florfenicol causes excessive lipid peroxidation and apoptosis induced renal injury in broilers. Ecotoxicol Environ Saf. (2020) 207:111282. doi: 10.1016/j.ecoenv.2020.1 11282

Conflict of Interest: The authors declare that the research was conducted in the absence of any commercial or financial relationships that could be construed as a potential conflict of interest.

Publisher's Note: All claims expressed in this article are solely those of the authors and do not necessarily represent those of their affiliated organizations, or those of the publisher, the editors and the reviewers. Any product that may be evaluated in this article, or claim that may be made by its manufacturer, is not guaranteed or endorsed by the publisher.

Copyright (c) 2021 Wang, Yang, Martínez, Martínez, Lopez-Torres, MartínezLarrañaga, Wang, Anadón and Ares. This is an open-access article distributed under the terms of the Creative Commons Attribution License (CC BY). The use, distribution or reproduction in other forums is permitted, provided the original author(s) and the copyright owner(s) are credited and that the original publication in this journal is cited, in accordance with accepted academic practice. No use, distribution or reproduction is permitted which does not comply with these terms. 